\title{
Reproduction of Human Fibrous Dysplasia of Bone in Immunocompromised Mice by Transplanted Mosaics of Normal and Gs $\alpha$-mutated Skeletal Progenitor Cells
}

\author{
Paolo Bianco, ${ }^{\star \ddagger}$ Sergei A. Kuznetsov, ${ }^{\S}$ Mara Riminucci, ${ }^{\star \ddagger}$ Larry W. Fisher, ${ }^{\S}$ Allen M. Spiegel, ${ }^{\|}$and Pamela Gehron Robey ${ }^{\S}$ \\ *Department of Experimental Medicine, ${ }^{\ddagger}$ University of L'Aquila, L'Aquila 67100; University “La Sapienza,” Rome 00161, Italy; \\ ${ }^{\S}$ Craniofacial and Skeletal Diseases Branch, National Institute of Dental Research, "Metabolic Diseases Branch, National Institute of \\ Diabetes, and Digestive and Kidney Diseases, National Institutes of Health, Bethesda, Maryland 20892
}

\begin{abstract}
We have isolated progenitor cells from the stromal system of the fibrous dysplastic marrow of patients with McCuneAlbright Syndrome. Analysis of the Gs $\alpha$ gene from individual colonies provided direct evidence for the presence of two different genotypes within single fibrous dysplastic lesions: marrow stromal cells containing two normal Gs $\alpha$ alleles, and those containing one normal allele and an allele with an activating mutation. Transplantation of clonal populations of normal cells into the subcutis of immunocompromised mice resulted in normal ossicle formation. In contrast, transplantation of clonal populations of mutant cells always led to the loss of transplanted cells from the transplantation site and no ossicle formation. However, transplantation of a mixture of normal and mutant cells reproduced an abnormal ectopic ossicle recapitulating human fibrous dysplasia and providing an in vivo cellular model of this disease. These results provide experimental evidence for the necessity of both normal and mutant cells in the development of McCune-Albright Syndrome fibrous dysplastic lesions in bone. (J. Clin. Invest. 1998. 101:1737-1744.) Key words: McCune-Albright Syndrome $\bullet$ G protein • marrow stromal cells • transplantation • somatic mosaicism
\end{abstract}

\section{Introduction}

McCune-Albright Syndrome (MAS) ${ }^{1}$ (polyostotic fibrous dysplasia with associated endocrinopathies and skin hyperpigmentation; OMIM 174800) is a genetic, noninherited disease $(1,2)$ associated with activating missense mutations of the gene encoding the $\alpha$ subunit of the stimulatory G protein, Gs (3-5), whereby the normal arginine at position 201 (R201) is

\footnotetext{
Address correspondence to Pamela Gehron Robey, Ph.D., Craniofacial and Skeletal Diseases Branch, National Institute of Dental Research, National Institutes of Health, 30 Convent Drive MSC 4320, Bethesda, MD 20892. Phone: 301-496-4563; FAX: 301-402-0824; E-mail: probey@yoda.nidr.nih.gov

Received for publication 25 November 1997 and accepted in revised form 4 February 1998
}

1. Abbreviations used in this paper: CFU-F, colony-forming unit fibroblastic; MAS, McCune-Albright Syndrome; R201, arginine at position 201; R201C, arginine to cysteine mutation at position 201; $\mathrm{R} 201 \mathrm{H}$, arginine to histidine mutation at position 201; RT, reverse transcription.

The Journal of Clinical Investigation

Volume 101, Number 8, April 1998, 1737-1744

http://www.jci.org replaced by either a cysteine (R201C) or a histidine (R201H). The mutation is thought to occur postzygotically, thus leading to a somatic mosaic state (6). Gs $\alpha$ mutations have been demonstrated in the bone lesions (7-11), but the precise identity of the mutated cell type(s) in the bone environment has remained elusive.

While the discovery of the Gs $\alpha$ mutations at R201 (R201C or $\mathrm{R} 201 \mathrm{H}$ ) provides an etiology for the syndrome, the pathogenesis of the bone lesions is as yet unclear. Polyostotic fibrous dysplasia is a severe feature of MAS, resulting in deformity of limb and facial bones, pathologic fractures, and crippling. Recent data indicate that cells of the osteogenic lineage represent a prime target for the manifestation of the effects of Gs $\alpha$ mutations (12).

Progenitor cells of skeletal tissues (colony-forming unit fibroblastic, CFU-F), including bone and hematopoiesis-supporting bone marrow stroma, are found among the population of adherent cells isolated in vitro from postnatal bone marrow (marrow stromal cells) (13-16). Prevailing evidence confirms the ability of these cells to reconstruct a normal "ossicle" (i.e., a miniature of the bone/bone marrow organ in which both bone tissue and hematopoietic tissue are mutually arranged in the appropriate architecture) when transplanted into immunocompromised mice using appropriate carriers $(17,18)$. When transplanted in diffusion chambers, these cells form bone, cartilage, fibrous tissue, and occasionally fat $(15,19-21)$. To date, these studies have been largely limited to the use of cells from experimental animals, and have been aimed entirely at addressing issues related to the lineages of skeletal cells. But in addition to these types of studies, it is conceivable that as progenitors of skeletal elements, marrow stromal cells derived from individuals with various forms of genetic diseases of osteogenic cells can be used in such transplantation systems to reproduce pathological tissues.

Fibrous dysplasia of bone embodies characteristic changes in the structure and function of the bone/bone marrow organ, namely $(a)$ the replacement of the normal hematopoietic marrow and bone trabeculae by a highly cellular, fibrous tissue, not supportive of hematopoiesis and associated adipogenesis, and $(b)$ the production of irregular, abnormal, and mechanically unsound bony structures. We have hypothesized that these changes specifically represent the effects of Gs $\alpha$ mutations on the differentiation and function of progenitor cells of skeletal tissues (12). Therefore, mutated progenitor cells would subsequently create abnormal tissues as they progress through the developmental and maturational events normally recapitulated during bone modeling and remodeling processes $(22,23)$. We isolated clonogenic stromal cells (skeletal progenitor cells) from the fibrotic bone marrow of fibrous dysplastic lesions. By extending mutational analysis to the level of single CFU-Fs, we next demonstrated a mosaic of normal and mutated progenitor cells encrypted in the parent fibrous dysplastic bone lesion. Transplants of a mixture of normal and mu- 
tated skeletal progenitor cells (a mosaic) but not of a clonal population of mutated cells into immunocompromised mice resulted in the formation of a miniature human organ comprised of abnormal bone and marrow tissues which recapitulated the pathological features of fibrous dysplasia. These results provide experimental evidence for an independent pathogenetic role of somatic mosaicism in the development of fibrous dysplasia. By allowing for the development of a human pathological organ in immunocompromised mice, our approach also provides the first in vivo human cellular model of the disease.

\section{Methods}

Isolation and culture of marrow stromal cells. Fresh surgical specimens of bone lesions were obtained from three patients with MAS who underwent corrective surgery under a National Institutes of Health Institutional Review Board-approved protocol (97-DK-55), and normal marrow from age-matched donors (94-D-0188). Marrow stromal cell cultures were established as described previously (24). Briefly, cell suspensions were obtained by scraping bone containing marrow into nutrient medium consisting of $\alpha$ MEM (Biofluids, Inc., Rockville, MD) plus $20 \%$ FBS (Life Technologies, Inc., Gaithersburg, MD), glutamine, penicillin, and streptomycin (Biofluids, Inc.). A single cell suspension was prepared by pipetting, serial passage through needles of decreasing diameter and a cell sieve (70 $\mu \mathrm{m}$; Falcon Labware, Cockeysville, MD), and plated into $75-\mathrm{cm}^{2}$ flasks at high density $\left(0.67-6.7 \times 10^{5} / \mathrm{cm}^{2}\right)$ or $150-\mathrm{mm}^{2}$ petri dishes at low density $\left(0.0067-0.067 \times 10^{4} / \mathrm{cm}^{2}\right)$. Cells were cultured at $37^{\circ} \mathrm{C}$ in an atmosphere of $100 \%$ humidity and $5 \% \mathrm{CO}_{2}$. High density cultures were passaged on day 9 as described previously (24). From low density cultures, individual, well-separated colonies were selected for passage between day 13 to 17 (with media replacement at days 7 and 14) using cloning cylinders, and the number of cells was expanded by passaging as described previously (24).

Reverse transcription (RT) PCR using wild-type and mutated primer sets. RNA of marrow stromal cell cultures established from affected and unaffected tissue and from normal donors was prepared by extraction with RNA STAT 60 according to the manufacturer's recommendations (Tel-Test, Inc., Friendswood, TX). An $\sim 300$-bp sequence in the $\alpha$ subunit cDNA was chosen as the target for PCR amplification. Three $5^{\prime}$ oligonucleotide primers were designed based on the normal and mutated sequences of exon 8 of the Gs $\alpha$ gene. An additional single base mismatch towards the $3^{\prime}$ end was included to ensure that the normal mRNA was not primed by the mutated sequence. One single reverse primer complementary to a sequence from exon 11 was used in all the reactions. The RT-PCR primer sequences used were as follows: wild-type, 5'-GACCTGCTTCGCTGG*CG, Arg $\rightarrow$ His, 5'-GGACCTGCTTCGCTGG ${ }^{*} \mathrm{C}(\mathrm{A})$, and Arg $\rightarrow$ Cys, 5'-CAGGACCTGCTTCGCTC*C(T) (*denoting internal mismatching and parentheses denoting the base transition), and reverse, 5'-TCTTGCTTGTTGAGGAACAG. RT and PCR reactions were performed in $50 \mu \mathrm{l} \mathrm{vol}$, with $1 \mu \mathrm{g}$ total RNA as template using the rTth DNA polymerase EZ buffer pack kit (Perkin-Elmer Corp., Norwalk, CT) according to the manufacturer's instructions. The reaction mixture contained $1.5 \mathrm{mM} \mathrm{Mn}(\mathrm{OAc})_{2}$ and $100 \mathrm{pmol}$ of each primer in $50 \mathrm{mM}$ bicine buffer. After the RT step at $60^{\circ} \mathrm{C}$ for $30 \mathrm{~min}$, the cDNA was denatured at $94^{\circ} \mathrm{C}$ for $2 \mathrm{~min}$. The specific cDNA sequence was amplified by 35 cycles of denaturation at $94^{\circ} \mathrm{C}$ for $30 \mathrm{~s}$, annealing at $55^{\circ} \mathrm{C}$ for $30 \mathrm{~s}$, and extension at $72^{\circ} \mathrm{C}$ for $30 \mathrm{~s}$. The final extension time was $7.0 \mathrm{~min}$ at $72^{\circ} \mathrm{C}$.

DNA extraction and sequence analysis. DNA from marrow stromal cells was extracted by DNA NOW ${ }^{\circledR}$ according to the manufacturer's specification (Biogentex, Inc., Seabrook, TX). A 270-bp sequence of the Gs $\alpha$ gene containing the codon for Arg 201 was amplified in a standard PCR using Taq polymerase and the following primers: 5'-TGACTATGTGCCGAGCGA (forward, exon 7), and 5'-AACCATGATCTCTGTTATATAA (reverse, intron G). The amplified product was purified by Wizard PCR PREP DNA purification system (Promega Corp., Madison, WI) and sequenced by the dideoxy chain-termination methods using the ABI 370 automated DNA sequencer and the ABI PRISM dye terminator cycle sequencing ready reaction kit (Perkin-Elmer Corp.).

Transplants. Human marrow stromal cells (passages 2-4, 1.5-6.0 $\times$ $10^{6}$ cells) were loaded onto vehicles $\left(50-100-\mathrm{mm}^{2}\right.$ cube of Collagraft ${ }^{\circledR}$ [Zimmer, Warsaw, IN] or $40 \mathrm{mg}$ of hydroxyapatite/tricalcium phosphate powder from the Collagraft ${ }^{\circledR}$ kit) shown previously to support osteogenesis for transplantation of human stromal cells into immunocompromised mice (18). Briefly, after trypsin release, the cells were pelleted by centrifugation at $1,000 \mathrm{rpm}$ for $10 \mathrm{~min}$ and resuspended in 30-100 $\mu \mathrm{l}$ of growth medium. Cells attached to carriers were transplanted subcutaneously into the back of NIH-bg-nu-xidBR (beige) mice (Harlan Sprague Dawley Inc., Indianapolis, IN) under an institutionally approved protocol for the use and care of animals in research.

Histology. Transplants were harvested 6-8 wk after surgery, fixed and decalcified in Bouin's, and routinely embedded in paraffin. The human origin of tissues formed in the transplants was demonstrated by in situ hybridization using human-specific alu sequences as probe in transplants fixed in $4 \%$ formaldehyde in $0.1 \mathrm{M}$ phosphate buffer, $\mathrm{pH}$ 7.2, and decalcified in neutral solutions of EDTA. The humanspecific alu probe was prepared by PCR using previously reported primers, and conditions for nonradioactive in situ hybridization as detailed elsewhere (24).

Standard hematoxylin and eosin sections were used for both histological survey and for measurements of the amount of bone formed in the transplants. Eosin is an osteotropic fluorochrome that enables bone structures to be imaged vividly in fluorescence microscopy (25). Confocal fluorescence images of transplant sections were recorded in a confocal laser scanning microscopy system (Phoibos 1000; Sarastro, Stockholm) equipped with a 488-nm argon ion laser, and complemented with the ImageSpace ${ }^{\circledR}$ image-processing software. User-defined thresholds of fluorescence intensity allowed highlighting and selective measurement of the total pixels corresponding to either bone or soft tissues in each image, excluding the remnants of decalcified carrier particles and blank spaces. Thus, the percentage ratio of bone to nonbone tissue was obtained for each image. Each transplant section was scanned in its entirety, and at least three different sections were measured per transplant. Mean values from multiple sections were calculated for each transplant, and mean values of MAS versus control transplants were compared by $t$ test.

\section{Results}

Isolation and mutational analysis of clonogenic marrow stromal cells demonstrate that individual fibrous dysplastic lesions are composed of normal and mutant cells (somatic mosaic). Single cell suspensions were prepared from samples of lesional fibrotic marrow of fibrous dysplastic tissues, and from bone marrow samples of normal donors using an established protocol (26). Plating of such cell suspensions at high density resulted in the formation of stromal cell monolayers from both normal and MAS samples. Low density cultures established from MAS samples resulted in the formation of discrete colonies of stromal cells in a similar fashion to low density cultures of normal bone marrow. An increasing number of discrete colonies was observed with increasing concentrations of nucleated cells plated (Fig. $1 A$ ). These results indicate that the lesional fibrotic marrow tissue of fibrous dysplasia, not unlike the normal bone marrow, contains stromal cells with clonogenic properties (CFU-F). Compared with normal marrow, MAS stromal cell preparations were characterized by a sub- 
A
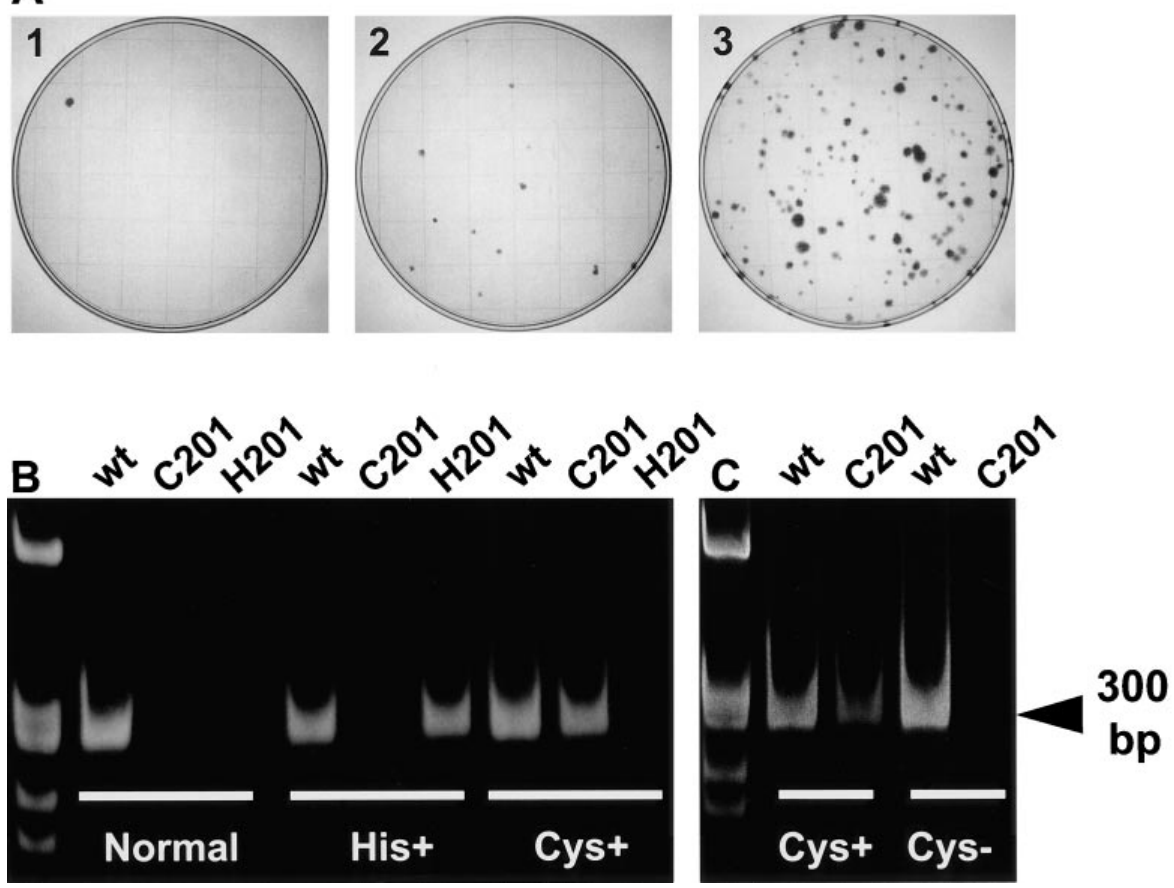

Figure 1. Clonogenic nature and identification of Gs $\alpha$ mutations in stromal cells isolated from fibrous dysplastic lesions from patients with MAS. $(A)$ Increasing numbers of marrow stromal colonies, the progeny of a single CFU-F, were generated by plating increasing concentrations $(1,3 \times$ $\left.10^{3} ; 2,3 \times 10^{4} ; 3,3 \times 10^{5}\right)$ of single cell suspensions isolated from the marrow of fibrous dysplastic lesions. (B) RT-PCR amplification using allele-specific primer sets described in Methods predicts the generation of an amplification product of $\sim 300$ bp. Using mRNA from normal stromal cultures, there was amplification with only the wild-type primer set and not with either of the mutated primer sets. Amplification of the wild-type allele was found in mRNA from patient 2 (His mutation) and from patient 1 (Cys mutation), consistent with the fact that mutant cells contain one normal allele. The R201H primer set produced amplification in patient 2 (and also patient 3, data not shown), but not patient 1 , and the R201C primer set amplified in patient 1 , but not in patient 2 or 3 . (C) RNA was extracted from individual colo-

nies of the same low density stromal cell culture from patient 1 . RT-PCR using allele-specific primers demonstrates the coexistence of both mutation-positive and mutation-negative colonies. $w t$, Wild-type.

stantially higher colony-forming efficiency consistent with an increased frequency of progenitor cells in the abnormal fibrous dysplastic marrow.

Mutations of the Gs $\alpha$ gene in strains of MAS stromal cells were detected by an RT-PCR technique using primer sets designed to amplify either the wild-type allele, or the R201C or R201H alleles (Fig. 1 B). As expected, the normal allele was detected in mRNA from both normal control and MAS cells. However, no amplification with either mutant primer sets was obtained in the normal control. Patient 1 was found to bear the Cys mutation, whereas patients 2 and 3 carried the His mutation. The same results were obtained by DNA sequencing of genomic DNA generated by PCR amplification of exon 8 .

Individual marrow stromal colonies from low density cultures were further expanded and analyzed for the presence or absence of mutation by RT-PCR. This demonstrated the coexistence of varied proportions (depending on the patient) of mutation-positive and mutation-negative colonies in individual cultures (Fig. $1 C$ ) and therefore the existence of a mosaic of normal and mutant CFU-Fs in both the parent cell suspensions and in the original lesional tissue samples.

Transplantation of a mosaic of normal and mutant stromal cells in immunocompromised mice results in the production of a human fibrous dysplastic ossicle. Cells obtained from high density cultures of MAS stromal cells (total polyclonal population), as well as cells from strains prepared from marrow samples of age-matched normal donors, were attached to carrier particles and transplanted subcutaneously into the backs of immunocompromised mice (Fig. 2). The transplants were harvested after 6-8 wk, and the histology of the tissues formed was assessed (Table I, and Figs. 3 and 4).

Substantial amounts of bone were observed in 14 of 14 transplants of polyclonal normal marrow stromal cells. The newly formed bone tissue, deposited onto carrier surfaces, encased areas of hematopoiesis, thus reproducing the architectural arrangement of normal trabecular bone harboring red marrow (Fig. $3 a$ ). Erythropoiesis, granulocytopoiesis, and megakaryocytes were consistently detected within the marrow tissue, indicating complete support of hematopoiesis within the newly formed ossicle. Typical marrow adipocytes were also obvious in all cases (Fig. 3 b). In many instances (10 of 14), the newly formed bone was found to be obviously lamellar in structure as observed by polarized light microscopy (Fig. 4, $a$ and $b)$.

Evidence of bone formation was observed in 11 of 22 transplants of polyclonal MAS stromal cells. Overall, the amount of bone tissue was scant in all instances, and most often limited to a thin rim of osteoid tissue covering the surfaces of carrier particles (Fig. 3, $c$ and $d$ ). Histomorphometric measurements of the amount of bone formed demonstrated a significant reduction in MAS transplants compared with controls (Table I). By polarized light microscopy, the MAS ectopic bone was always woven instead of lamellar in character (Fig. 4, $c$ and $d$ ). On occasion, collagen bundles (Sharpey fibers) and cells oriented perpendicular to the carrier/bone were identified in the MAS transplant surfaces. These structures are histological features characteristic of fibrous dysplasia of bone (12). No hematopoiesis was observed in transplants of MAS stromal cells at the time points examined during this study. Instead, spaces separating carrier particles, whether associated with newly formed bone or not, were regularly filled with a richly cellular, fibrotic tissue. No adipocytes were observed within this fibrotic tissue (Figs. 3 and 4).

Transplantation of homogeneous mutated stromal cell 


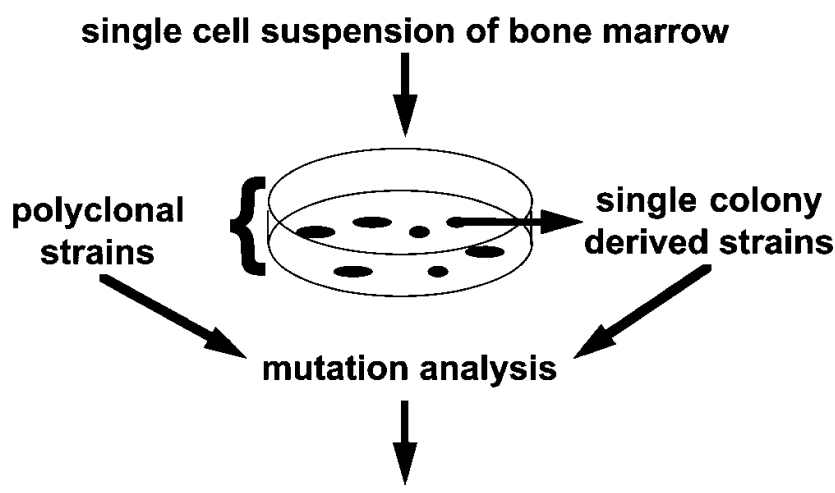

attach cells to ceramic particles

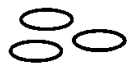

subcutaneous transplantation into immunocompromised mice

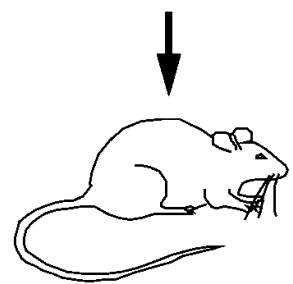

histological evaluation, 6-8 weeks

Figure 2. Scheme of transplantation of in vitro-expanded marrow stromal cells into immunocompromised mice. Cells were prepared from marrow of either normal donors or from fibrous dysplastic tissue from patients with MAS, and plated at high density for the generation of polyclonal derived strains, or at low density for the isolation of single colony-derived strains. After several passages to generate a sufficient number of cells, cells were attached to particles composed of hydroxyapatite/tricalcium phosphate and subsequently transplanted subcutaneously into the backs of immunocompromised mice. Transplants were harvested 6-8 wk later and evaluated histologically.

strains from MAS in immunocompromised mice results in graft failure. Since a 1:1 ratio of normal to mutated bases (C:T for the $\mathrm{R}$ to $\mathrm{C}$ mutation, $\mathrm{G}: \mathrm{A}$ for the $\mathrm{R}$ to $\mathrm{H}$ mutation) is predicted in a cell population comprised of $100 \%$ mutant cells, sequencing of PCR-amplified DNA using genomic DNA extracted from single colonies as template was used to verify that the cloned population was predominantly a homogeneous population of mutant cells. Using this approach, we identified

Table I. Summary of Results of Transplantation of $M A S-$ derived and Normal Stromal Cell Strains in Immunocompromised Mice

\begin{tabular}{|c|c|c|c|c|c|c|}
\hline & Patients & $\begin{array}{l}\text { Trans- } \\
\text { plants }\end{array}$ & $\begin{array}{l}\text { Transplants } \\
\text { with bone }\end{array}$ & $\begin{array}{l}\text { Transplants } \\
\text { with } \\
\text { hematopoiesis }\end{array}$ & $\begin{array}{l}\text { Transplants } \\
\text { with } \\
\text { adipocytes }\end{array}$ & Percent bone \\
\hline & & & & & & mean $\pm S E$ \\
\hline MAS & 3 & 22 & 11 & 0 & 0 & $2.29 \pm 0.85$ \\
\hline Control & 5 & 14 & 14 & 14 & 14 & $25.31 \pm 4.41$ \\
\hline
\end{tabular}

colonies comprised entirely of normal cells, other colonies composed entirely of mutant cells, and some colonies comprised of a mixture of mutation-positive and mutation-negative cells (Fig. 5). Homogeneous mutant colonies were used to assess their behavior in the in vivo transplantation assay compared with normal cells, as well as with mixed populations of normal and mutant cells (mosaic).

When cell strains composed entirely of mutant cells were transplanted (six transplants from two different clonal strains), no bone was formed (Fig. $5 b$ ), and no evidence of osteogenic, myelogenic, or adipogenic differentiation was observed, similar to what is observed by transplantation of the vehicle alone (data not shown). A prominent giant cell inflammatory reaction (foreign body type) to carrier particles was a conspicuous feature. A dense, poorly cellular, fibrotic tissue filled the spaces between carrier particles. Results of in situ hybridization experiments using a human specific alu sequence as probe indicated that no human cells could be localized in these transplants. Thus, neither bone nor any other human tissue were formed by homogeneous populations of mutant cells (Fig. $5 d$ ). Bone formation was observed when a mutation-free cell strain derived from a different colony from the same patient was transplanted (data not shown). Likewise, in transplants of colonies proven by DNA sequencing to consist of a mosaic (mutant and nonmutant cells) rather than a clonal population, low amounts of bone (Fig. $5 a$ ) were formed by human cells (Fig. 5 c), similar to that formed by polyclonal populations of MAS stromal cells. Neither hematopoiesis nor adipogenesis was observed in these transplants.

\section{Discussion}

The purpose of this study was to demonstrate the ability of mutated skeletal progenitor cells (marrow stromal cells) to recapitulate abnormal bone formation using a novel in vivo transplantation model system. We hypothesized that these progenitor cells, found in the postnatal organism and providing the reservoir for bone growth and remodeling, could be found in pathological tissues and would be directly involved in establishing bone disease. Specifically in MAS, the hypothesis was that mutated skeletal progenitor cells would reside in the abnormal marrow in fibrous dysplastic lesions of bone. Because a normal ossicle is formed consistently by virtually all polyclonal strains of normal marrow stromal cells transplanted into immunocompromised mice $(17,18,21,24)$, we postulated that an abnormal fibrous dysplastic ossicle would be formed if populations of mutated stromal cells from MAS were transplanted.

We assumed that the abnormal fibrotic tissue associated with abnormal bone trabeculae in fibrous dysplastic lesions could be regarded as a pathological marrow tissue from which clonogenic skeletal progenitor cells (CFU-F) including stromal cells could be isolated in culture. Clonogenic cells were isolated with high efficiency from the fibrous dysplastic tissue and proven to carry the activating Gs $\alpha$ mutations, thus confirming that mutated stromal cells were found in fibrous dysplastic tissue. Upon transplantation into immunocompromised mice, polyclonal strains of stromal cells derived from fibrous dysplastic bone of MAS patients generated abnormal ossicles. Formation of new bone was quantitatively and qualitatively abnormal in MAS transplants, and reproduced even subtle histological features of fibrous dysplasia. A hematopoietic mar- 

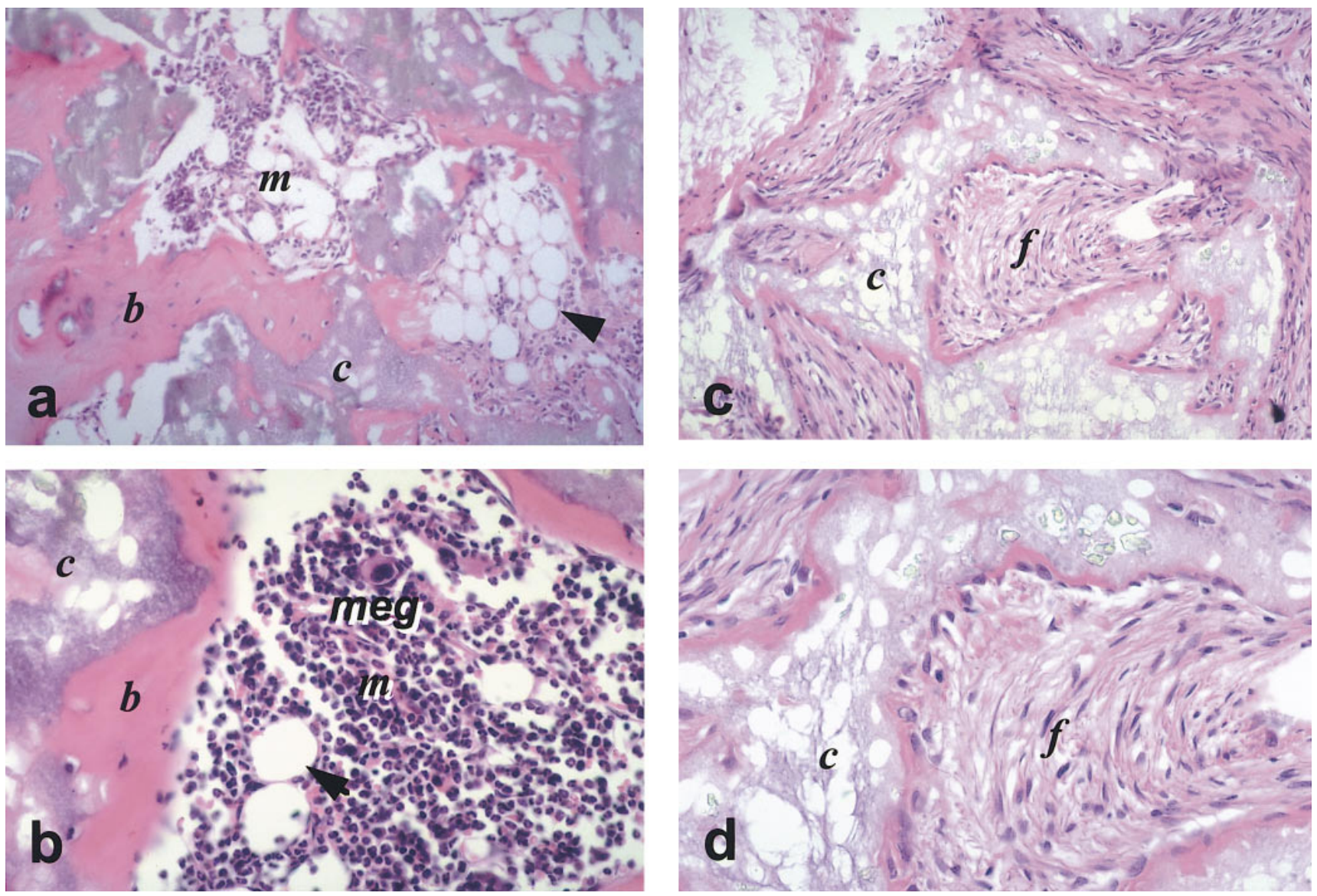

Figure 3. Histology of ectopic ossicles formed by normal and MAS stromal cells. ( $a$ and $b$ ) Representative histological sections of ectopic ossicles formed by transplanted normal polyclonal marrow stromal cells in immunocompromised mice, harvested at 8 wk. Substantial amounts of bone $(b)$ are formed onto the surface of carrier particles $(c)$. Spaces separating newly formed bony structures are occupied by hematopoietic marrow $(m)$, in which all hematopoietic lines are detected (meg, megakaryocyte). Adipocytes are readily recognizable in the ectopic marrow ( $a r-$ rowheads). $(c$ and $d$ ) Representative histological sections of ectopic ossicle formed by transplanted polyclonal marrow stromal cells from fibrous dysplastic bone, harvested at $8 \mathrm{wk}$. Bone formation is limited to a thin rim of osteoid tissue covering the carrier surfaces. Hematopoiesis is absent, and the spaces separating bone/carrier particles $(c)$ are occupied by fibrous tissue $(f)$.

row did not develop in the ossicles, and no adipogenesis was ever observed. Taken together, these features mimic closely the basic tissue changes characterizing human fibrous dysplasia, which essentially consist of the progressive replacement of normal hematopoietic/adipose marrow and normal bone by a highly cellular, nonhematopoietic fibrotic tissue interspersed with thin, newly formed but mechanically unsound bone trabeculae. These changes are most likely due to the influence of excess levels of cAMP produced by the mutated Gs $\alpha$, a protein that is highly upregulated as progenitor cells become fully mature osteoblasts (12). Excess cAMP has been found to evoke a dramatic change in osteoblastic cell shape and cell-matrix interaction (reference 12, and our unpublished observations), and may account for the abnormal deposition of collagen fibers perpendicular instead of colinear to the bone-forming surface, as has been noted both in fibrous dysplastic tissue and in the transplants generated in this study. Furthermore, presence of the Gs $\alpha$ mutation appears to prevent the differentiation of marrow stromal cells into hematopoiesis-supportive stroma and associated adipocytes as would occur in ossicles formed by normal marrow stromal cells. While the exact mechanism for this lack of progression is not known, it may be due to the fact that hematopoiesis and associated adipogenesis cannot be established until a certain threshold level of bone has been deposited, and the amount of bone formed by MAS stromal cells was inadequate. However, it is also possible that increased levels of cAMP generated by the mutated Gs $\alpha$ may directly inhibit the differentiation of transplanted cells into hematopoiesis-supportive stroma and adipocytes. Indeed, adipogenesis is generally associated with reduced levels of Gs $\alpha(27,28)$, and inhibition of Gs $\alpha$ promotes adipogenesis (29). Furthermore, activation of Gs $\alpha$ by ADP-ribosylation through the action of cholera toxin blocks adipogenesis (29).

Taking advantage of the ability of individual skeletal progenitor cells to give rise to discrete stromal cell colonies when plated in vitro, we could extend the analysis of Gs $\alpha$ mutations to the level of single CFU-Fs. The coexistence of normal and mutated colonies in individual cultures provides direct demonstration of the occurrence of a mosaic of normal and mutated CFU-Fs in the parent lesional tissue. The notion that MAS represents an instance of somatic mosaicism throughout the body is well-established. However, our finding establishes that 

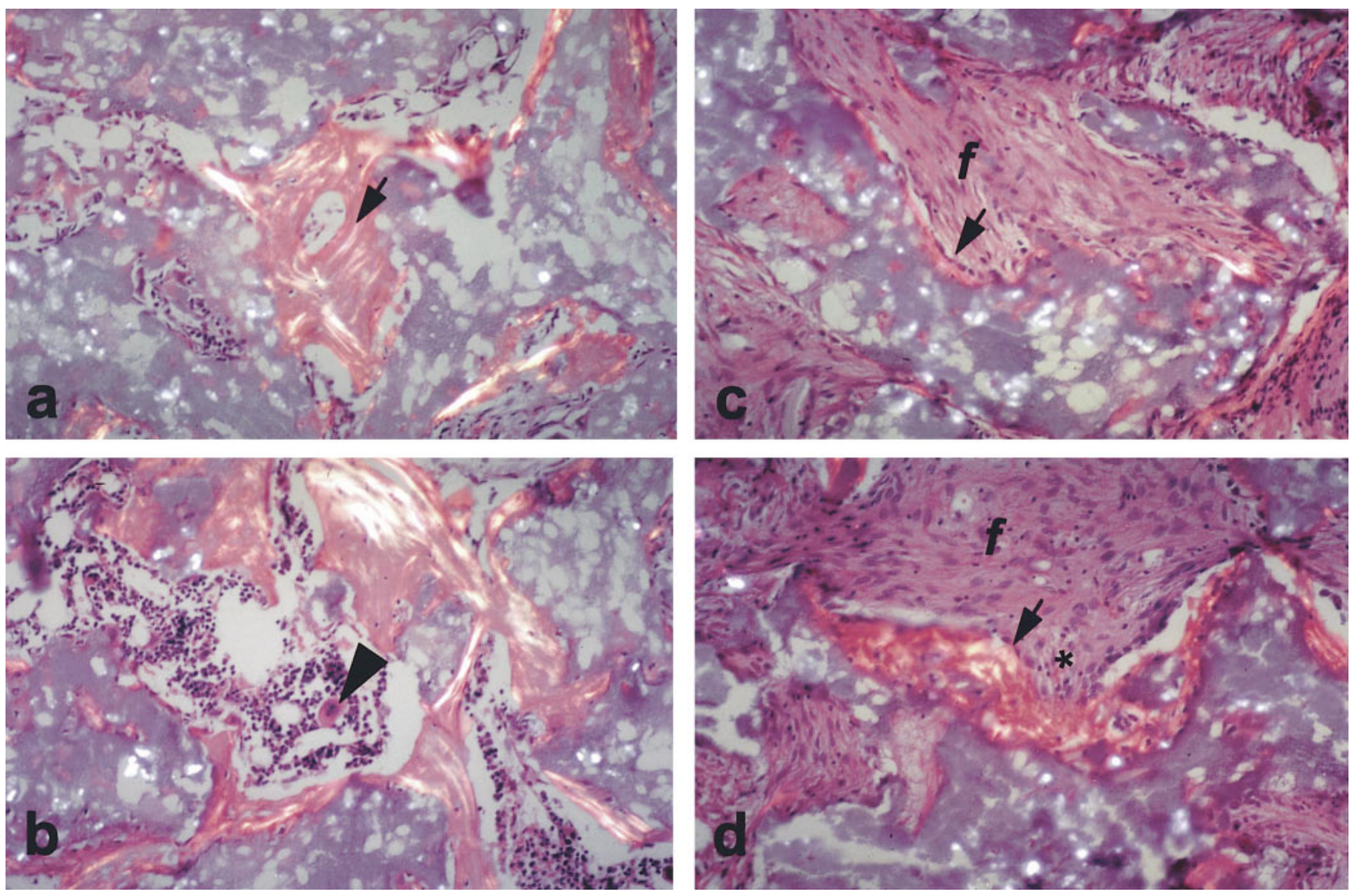

Figure 4. Structure of ectopic bone formed by normal and MAS stromal cells. Polarized light microscopy views of sections of ectopic ossicles formed by normal polyclonal stromal cells $(a$ and $b$ ) or MAS-derived polyclonal stromal cells in immunocompromised mice $(c$ and $d$ ). Note the lamellar structure (similar to normal postnatal trabecular bone) of bone in $a$ and $b$ (arrow in $a$ ). Arrowhead in $b$, A megakaryocyte in the ectopic bone marrow. In contrast, the woven structure of bone in $c$ and $d$ is similar to the woven bone found in fibrous dysplasia, along with a fibrous tissue $(f)$ instead of hematopoietic marrow. Several Sharpey fibers, collagen bundles oriented perpendicular to the forming surface $(d$, below aster$i s k$, which are a prominent finding in fibrous dysplasia, are also observed.

an individual fibrous dysplastic lesion is a mosaic in itself, rather than the abnormal tissue composed of a homogeneous population of mutated cells. Preliminary data using allele-specific RT-PCR in situ hybridization as applied to sections of fibrous dysplasia are fully consistent with our in vitro findings (data not shown). An important implication of this finding reads that fibrous dysplastic lesions in MAS do not arise as the clonal expansion of a single mutant cell, as has been suggested in other types of abnormal cell growth associated with either the R201C or the R201H mutation of the Gs $\alpha$ gene $(5,30)$.

When transplanted into immunocompromised mice, two different strains of mutant cells did not give rise to either a normal or an abnormal ossicle. Mutated cells did not survive, and neither bone nor fibrous tissue of human origin could be observed in the transplants. Mutations of the Gs $\alpha$ gene are regarded as "dominant lethal," i.e., incompatible with viability of the conceptus if they occur as germline mutations (6). In this view, mosaicism represents the only possible means for the mutant gene to survive. Our data suggest that a mosaic of normal and mutated cells may indeed be required in our system for both the survival of mutated cells and the development of a miniature version of human fibrous dysplasia. Thus, not only are the native fibrous dysplastic lesions observed in MAS pa- tients composed of a mosaic of normal and mutant cells, but the mosaic may also be required for a fibrous dysplastic lesion to actually develop. Mutant cells may recruit normal cells to participate in the formation of the lesion through direct cellcell communication. It is well-known that osteoblastic cells are linked via gap junctions (31) through which small molecules such as cAMP can diffuse. Consequently, mutant cells linked to normal cells may alter their metabolism. Another possibility is that mutant cells influence the behavior of the normal cell population through the production of growth factors and/or cytokines. For example, it has been found that MAS cells produce increased levels of IL-6 (10), which may also alter the metabolism of neighboring normal cells.

In conclusion, our study substantiates the hypothesis that skeletal lesions in fibrous dysplasia (and likely also in other genetic diseases of the skeleton) develop as a result of the effects of mutations on skeletal progenitor cells (CFU-F, marrow stromal cells). Thus, these cells can be transplanted to reproduce, in experimental animals, human living pathological skeletal organs (bone and bone marrow). Using this approach, we have provided evidence for an independent pathogenetic role of somatic mosaicism in the development of fibrous dysplasia of bone associated with activating mutations of the Gs $\alpha$ gene. 
$H \& E$
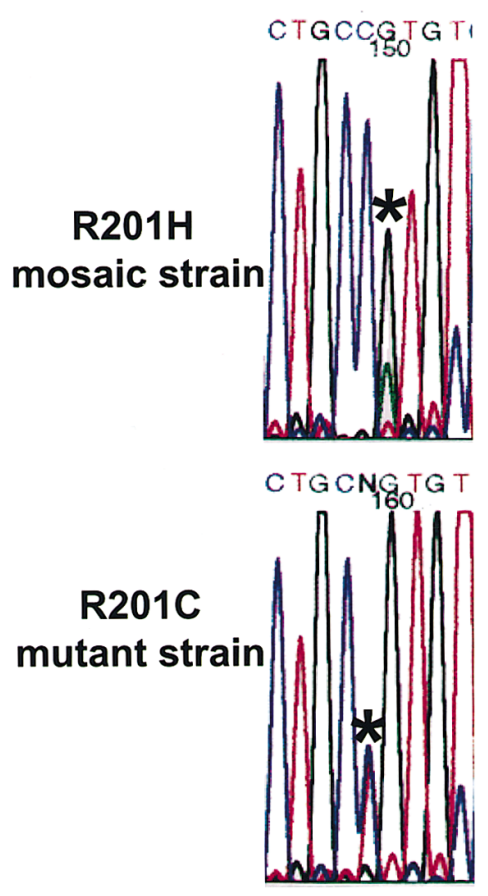
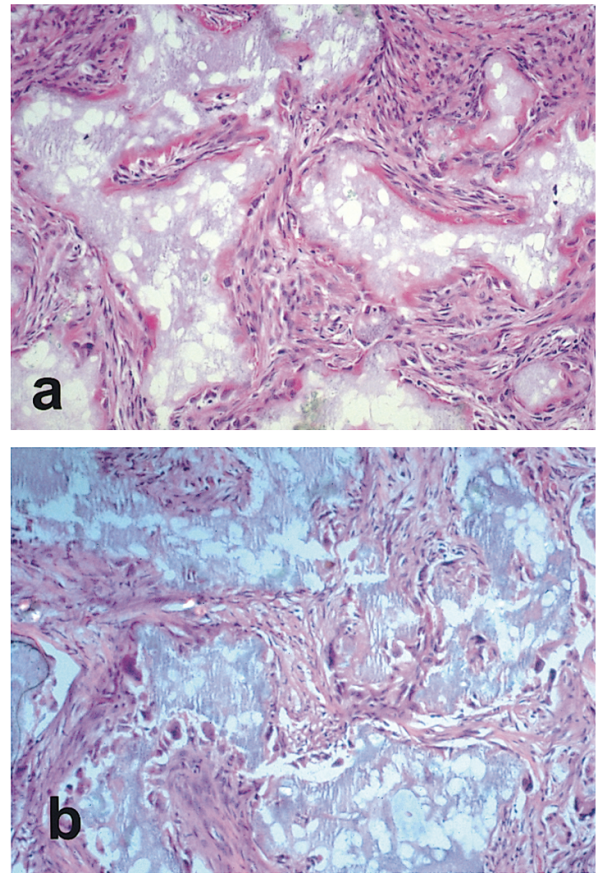

Human Alu seq
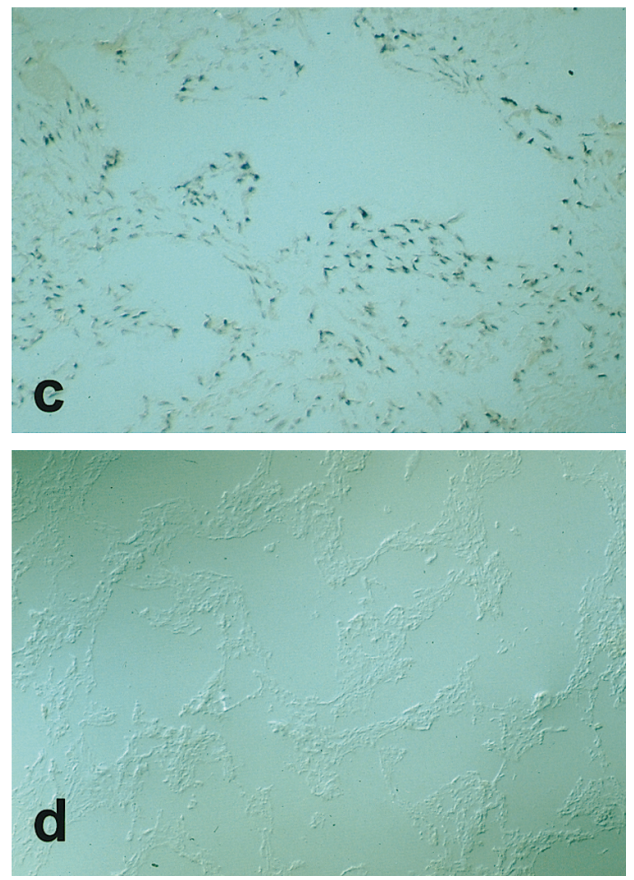

Figure 5. Comparison of ossicles formed by mosaic (normal and mutant) and $100 \%$ mutant strains. Transplantation of a mosaic strain (normal to mutated base ratio $>1: 1$ as determined by DNA sequencing) results in an abnormal ossicle with fibrous dysplastic-like histology (a). Cells in the fibrous tissue and along bony surfaces are human in origin, as indicated by hybridization with a human-specific alu probe $(c)$. In contrast, transplantation of a mutant strain (normal to mutated base ratio $=1: 1$ as determined by DNA sequencing) results in the loss of human cells (no signal by in situ hybridization for human-specific alu sequences $(d)$. Therefore, the tissue found in the transplant $(b)$ is of mouse origin. Note the absence of osteoid rimming along the surface of carrier particles, which are instead associated with reactive giant cells. $H \& E$, Hematoxylin and eosin.

This approach lends itself to broader applications to many genetic and nongenetic diseases of bone (osteogenic cell diseases), with obvious implications for assessment of pathogenetic mechanisms and the development and evaluation of novel treatments (32), including genetic manipulations.

\section{Acknowledgments}

The authors would like to acknowledge Dr. C. Dufrense (Fairfax Hospital, Fairfax, VA), Dr. A. Wolf (Miami Children's Hospital, Miami, FL), and Dr. P.K. Patel and Dr. A. Shenker (Children's Memorial Hospital, Chicago, IL) for providing us with fresh patient material for this study.

This work was supported in part by a Telethon Italia grant to P. Bianco (E.519).

\section{References}

1. Albright, F., A.M. Butler, A.O. Hampton, and P. Smith. 1937. Syndrome characterized by osteitis fibrosa disseminata, areas of pigmentation and endocrine dysfunction with precocious puberty in females. N. Engl. J. Med. 216:727746.

2. Danon, M., and J.D. Crawford. 1987. The McCune-Albright syndrome. Ergeb. Inn. Med. Kinderheilkd. 55:81-115.

3. Weinstein, L.S., A. Shenker, P.V. Gejman, M.J. Merino, E. Friedman, and A.M. Spiegel. 1991. Activating mutations of the stimulatory G protein in the McCune-Albright syndrome. N. Engl. J. Med. 325:1688-1695.

4. Schwindinger, W.F., C.A. Francomano, and M.A. Levine. 1992. Identifi- cation of a mutation in the gene encoding the alpha subunit of the stimulatory $\mathrm{G}$ protein of adenylyl cyclase in McCune-Albright syndrome. Proc. Natl. Acad. Sci. USA. 89:5152-5156.

5. Shenker, A., L.S. Weinstein, A. Moran, O.H. Pescovitz, N.J. Charest, C.M. Boney, J.J. Van Wyk, M.J. Merino, P.P. Feuillan, and A.M. Spiegel. 1993 Severe endocrine and nonendocrine manifestations of the McCune-Albright syndrome associated with activating mutations of stimulatory G protein GS. $J$. Pediatr. 123:509-518.

6. Happle, R. 1986. The McCune-Albright syndrome: a lethal gene surviving by mosaicism. Clin. Genet. 29:321-324.

7. Malchoff, C.D., G. Reardon, D.C. MacGillivray, H. Yamase, A.D. Rogol, and D.M. Malchoff. 1994. An unusual presentation of McCune-Albright syndrome confirmed by an activating mutation of the Gs alpha-subunit from a bone lesion. J. Clin. Endocrinol. Metab. 78:803-806.

8. Shenker, A., L.S. Weinstein, D.E. Sweet, and A.M. Spiegel. 1994. An activating Gs alpha mutation is present in fibrous dysplasia of bone in the McCune-Albright syndrome. J. Clin. Endocrinol. Metab. 79:750-775.

9. Candeliere, G.A., F.H. Glorieux, J. Prud'homme, and R. St.-Arnaud. 1995. Increased expression of the c-fos proto-oncogene in bone from patients with fibrous dysplasia. N. Engl. J. Med. 332:1546-1551.

10. Yamamoto, T., K. Ozono, S. Kasayama, K. Yoh, K. Hiroshima, M. Takagi, S. Matsumoto, T. Michigami, K. Yamaoka, T. Kishimoto, and S. Okada. 1996. Increased IL-6-production by cells isolated from the fibrous bone dysplasia tissues in patients with McCune-Albright syndrome. J. Clin. Invest. 98:30-35.

11. Marie, P.J., C. de Pollak, P. Chanson, and A. Lomri. 1997. Increased proliferation of osteoblastic cells expressing the activating Gs alpha mutation in monostotic and polyostotic fibrous dysplasia. Am. J. Pathol. 150:1059-1069.

12. Riminucci, M., L.W. Fisher, A. Shenker, A.S. Spiegel, P. Bianco, and P.G. Robey. 1997. Fibrous dysplasia of bone in the McCune-Albright Syndrome: abnormalities in bone formation. Am. J. Pathol. 151:1587-1600.

13. Friedenstein, A.J., I.I. Piatezky-Shapiro, and K.V. Petrakova. 1966. Osteogenesis in transplants of bone marrow cells. J. Embryol. Exp. Morphol. 16: 381-390.

14. Friedenstein, A.J. 1980. Stromal mechanisms of bone marrow: cloning 
in vitro and retransplantation in vivo. Hamatol. Bluttransfus. 25:19-29.

15. Owen, M. 1988. Marrow stromal stem cells. J. Cell. Sci. Suppl. 10:63-76.

16. Owen, M., and A.J. Friedenstein. 1988. Stromal stem cells: marrowderived osteogenic precursors. Ciba Found. Symp. 136:42-60.

17. Goshima, J., V.M. Goldberg, and A.I. Caplan. 1991. Osteogenic potential of culture-expanded rat marrow cells as assayed in vivo with porous calcium phosphate ceramic. Biomaterials. 12:253-258.

18. Krebsbach, P.H., S.A. Kuznetsov, K. Satomura, R.V. Emmons, D.W. Rowe, and P.G. Robey. 1997. Bone formation in vivo: comparison of osteogenesis by transplanted mouse and human marrow stromal fibroblasts. Transplantation (Baltimore). 63:1059-1069.

19. Friedenstein, A.J., R.K. Chailakhyan, and U.V. Gerasimov. 1987. Bone marrow osteogenic stem cells: in vitro cultivation and transplantation in diffusion chambers. Cell Tissue Kinet. 20:263-277.

20. Ashton, B.A. T.D. Allen, C.R. Howlett, C.C. Eaglesom, A. Hattori, and M. Owen. 1980. Formation of bone and cartilage by marrow stromal cells in diffusion chambers in vivo. Clin. Orthop. 151:294-307.

21. Haynesworth, S.E., J. Goshima, V.M. Goldberg, and A.I. Caplan. 1992. Characterization of cells with osteogenic potential from human marrow. Bone (NY). 13:81-88.

22. Bianco, P., and M. Riminucci. 1998. Morphology and behaviour of marrow stromal cells in vivo in health and disease. In Marrow Stromal Cell Cultures. J.N. Beresford and M.A. Owen, editors. Cambridge University Press, Cambridge. 10-25.

23. Robey, P.G., P. Bianco, and J.D. Termine. 1992. The cell biology and molecular biochemistry of bone formation. In Disorders of Mineral Metabolism. M.J. Favus and F.L. Coe, editors. Raven Press, Ltd., New York. 241-263.
24. Kuznetsov, S.A., P.H. Krebsbach, K. Satomura, J. Kerr, M. Riminucci, D. Benayahu, and P.G. Robey. 1997. Single-colony derived strains of human marrow stromal fibroblasts form bone after transplantation in vivo. J. Bone Miner. Res. 12:1335-1347.

25. Bradbeer, J.N., M. Riminucci, and P. Bianco. 1994. Giemsa as a fluorescent stain for mineralized bone. J. Histochem. Cytochem. 42:677-680.

26. Kuznetsov, S., and P.G. Robey. 1996. Species differences in growth requirements for bone marrow stromal fibroblast colony formation in vitro. Calcif. Tissue Int. 59:265-270.

27. Gettys, T.W., V. Ramkumar, R.J. Uhing, L. Seger, and I.L. Taylor. 1991. Alterations in mRNA levels, expression, and function of GTP-binding regulatory proteins in adipocytes from obese mice (C57BL/6J-ob/ob). J. Biol. Chem. 266:15949-15955.

28. Wang, H.Y., and C.C. Malbon. 1996. The Gs alpha/Gi alpha 2 axis controls adipogenesis independently of adenylylcyclase. Int. J. Obes. Relat. Metab. Disord. 20:S26-S31.

29. Wang, H.Y., D.C. Watkins, and C.C. Malbon. 1992. Antisense oligodeoxynucleotides to GS protein alpha-subunit sequence accelerate differentiation of fibroblasts to adipocytes. Nature. 358:334-337.

30. Spiegel, A.M. 1997. The molecular basis of disorders caused by defects in G proteins. Horm. Res. 47:89-96.

31. Jones, S.J., C. Gray, H. Sakamaki, M. Arora, A. Boyde, R. Gourdie, and C. Green. 1993. The incidence and size of gap junctions between the bone cells in rat calvaria. Anat. Embryol. 187:343-352.

32. Liens, D., P.D. Delmas, and P.J. Meunier. 1994. Long-term effects of intravenous pamidronate in fibrous dysplasia of bone. Lancet. 343:953-954. 